\title{
THE ARGUMENT FROM CONSCIOUSNESS AND DIVINE CONSCIOUSNESS
}

\section{THOMAS SCHÄRTL}

Augsburg University

\begin{abstract}
The paper aims for an improvement of the so-called argument from consciousness while focusing on the first-person-perspective as a unique feature of consciousness that opens the floor for a theistic explanation. As a side effect of knowledge arguments, which are necessary to keep a posterior materialism off bounds, the paper proposes an interpretation of divine knowledge as knowledge of things rather than knowledge of facts.
\end{abstract}

\section{SETTING THE STAGE}

Some philosophers who have dealt with the argument from consciousness have called it a God of the gaps argument. ${ }^{1}$ Indeed, there is little doubt about the fact that the argument from consciousness (AfC) is a version of an argument from design. Its aim is, among others, to offer a contrast to non-theistic naturalism as it has been presented by Dennett and others.

James P. Moreland has re-furnished AfC along the following lines (earlier versions of it have been crafted by Robert Adams and Richard Swinburne): ${ }^{2}$

'(1) Genuinely nonphysical mental states exist.

(2) There is an explanation for the existence of mental states.

(3) Personal explanation is different from natural scientific explanation.

(4) The explanation for the existence of mental states is either a personal or natural scientific explanation.

1 See for example Daniel Lim, 'Zombies, Ephiphenomenalism, and Personal Explanations: A Tension in Moreland's Argument from Consciousness', EJPR, 3 (2011), 439-450; see also J.P. Moreland, 'God and the Argument from Consciousness: A Response to Lim', EJPR, 4 (2012), 243-251.

${ }^{2}$ See Robert Adams, The Virtue of Faith and Other Essays in Philosophical Theology (Oxford: Oxford University Press, 1987); Richard Swinburne, The Existence of God, 2nd edition (Oxford: Oxford University Press, 2004). 
(5) The explanation is not a natural scientific one.

(6) Therefore, the explanation is a personal one.

(7) If the explanation is personal, then it is theistic.

(8) Therefore the explanation is theistic.'

Most of Moreland's premises are subject to a number of objections. It is not within the scope of this paper to list all of them or to discuss each of them in detail. But it is, nevertheless, necessary to point to the most serious of them. One of those objections is the rebuttal of the very first premise: Physicalists of any denomination would argue that this proposition is wrong. And defenders of AfC would have to show that there are, indeed, genuinely nonphysical states or facts while mentioning, for example, the existence of phenomenal or 'qualia-entrenched' consciousness for a start. Of course, if this is the only cornerstone of the argument it will remain open for endless discussions, as we know their parallels from the philosophy of mind. And, as Timothy O'Connor and Kevin Kimble have underlined recently, ${ }^{4} \mathrm{AfC}$ is in danger of seriously collapsing if one could come up with a purely naturalistic explanation of phenomenal consciousness. As a matter of fact, AfC's effort seems to depend on the argument's premise 1, which is plausible only if everybody will concede an explanatory gap between materialism on the one hand and the existence of genuinely nonphysical mental states on the other - a gap that offers enough space for theistic explanations. But if there are no genuinely mental states, the whole business of a non-natural explanation becomes rather useless.

This raises the more general question whether or not theism should put all its eggs in the basket of a non-physicalistic philosophy of mind (the latter phrase may be used to allow for a variety of models beyond the fence of eliminativism) and whether or not even a sophisticated Godof-the-gaps argument is bound to fail eventually. My sub-thesis in this paper will be that anyone who wants to come up with a more convincing version of $\mathrm{AfC}$ needs to move from phenomenal consciousness to 'higher' constituents or, let us call them, 'performances' of consciousness:

\footnotetext{
${ }^{3}$ James Porter Moreland, 'The Argument from Consciousness', in The Rationality of Theism, ed. by Paul Copan and Paul K. Moser (London - New York: Routledge, 2003), pp. 204-220 (esp. p. 206). See also James Porter Moreland, Consciousness and the Existence of God: A Theistic Argument (New York - London: Routledge, 2008), p. 37.

${ }^{4}$ Cf. Kevin Kimble and Timothy O' Connor, 'The Argument from Consciousness Revisited', in Oxford Studies in the Philosophy of Religion, Vol. 3, ed. by Jonathan Kvanvig (Oxford: Oxford University Press, 2011), pp. 110-141 (esp. 111-117).
} 
we should think of the experience of moral values or properties or the ontological implications of the first person perspective. However, this sub-thesis will be presented as some sort of conditional only: If there is something about consciousness which has the property $X$ then AfC might get off the ground. Still, up to today I don't really know whether or not there is enough evidence for $X$ and whether or not the two instances I will refer to deliver sufficient evidence. But even if we look at possible flaws right from the start, there is already some consolation available: In case the mentioned improvement of AfC might not work at all, any defender of AfC still has some options left. O'Connor and Kimble, for example, have introduced a prominent one: Even within a materialistic framework consciousness as a (nevertheless contingent and surprising phenomenon) could be taken as a hint towards a refreshed fine-tuningargument for the existence of God. ${ }^{5}$ Maybe this is all we can get. But we would also have to admit: In getting this, AfC will lose its assumedly privileged position and its fascinating quality.

However, in addition to my sub-thesis my main thesis will be that AfC's starting point - phenomenal knowledge and the puzzles of consciousness - can be helpful to say something more substantial about divine consciousness, at least by some sort of detour. The main inspiration is drawn from Yujin Nagasawa's book ${ }^{6}$ on knowledge arguments, which basically shows that the structures of knowledge arguments, as used in the philosophy of mind by Frank Jackson or Thomas Nagel, can be used to undermine the notion of divine omniscience if implemented within the philosophy of religion. My point will be that Michel Tye's recently endorsed strategy to deal with what is called 'phenomenal consciousness'7 in circumventing the highly problematic notion of 'phenomenal concepts' by introducing the difference between knowledge of things and knowledge of facts can offer an interesting way out of what we might call Nagasawa's trap. While Tye, as I mentioned before, uses the difference between knowledge of things and knowledge of facts, a distinction he claims to have borrowed from Bertrand Russell, ${ }^{8} \mathrm{I}$ am going to draw

${ }^{5}$ See Kimble - O’Connor, 'The Argument from Consciousness', pp. 137-138.

${ }^{6}$ Cf. Yujin Nagasawa, God and Phenomenal Consciousness: A Novel Approach to Knowledge Arguments (Cambridge: Cambridge University Press, 2008), pp. 3-14.

${ }^{7}$ Michael Tye, Consciousness Revisited: Materialism Without Phenomenal Concepts (London - Cambridge: MIT Press, 2009).

8 Bertrand Russell, The Problems of Philosophy (New York: Dover Publications, 1999), pp. 31-40. It is important to note that Russell himself talks about knowledge 
a distinction between knowledge of essences and knowledge of propositions while trying to get a helping hand from Thomas Aquinas ${ }^{9}$ and, most of all, from John Duns Scotus. ${ }^{10}$

But let's return to the outlines of AfC. The main objection points to the fact that AfC has some serious problems to get off the ground. Choosing the premises to start from is one of its key problems because these premises have to prepare for the conclusion that theism offers a better explanation to consciousness than naturalism does. Let us take a look at two key propositions that may be used as starting premises for AfC:

(1) If consciousness has a certain property or feature $X$, naturalistic explanation is not sufficient.

(2) Either theistic or naturalistic explanation is sufficient.

Once we transform (2) into

$\left(2^{*}\right)$ If a naturalistic explanation isn't sufficient, then only a theistic explanation suffices

we will arrive at:

(3) If consciousness has a certain property or feature $X$, then only a theistic explanation suffices.

Recent discussions of AfC have pointed directly to the core problems that are necessarily associated with premises (1) and (2): Is there something genuine about consciousness, which would exceed the framework of naturalism? And what exactly would it mean to say that a naturalistic explanation is not sufficient?

\section{PHENOMENAL CONTENT}

Timothy O'Connor and Kevin Kimble have shown that the best candidate for the idea premise (1) is hinting at might be the phenomenal content of experience. ${ }^{11}$ Indeed, at first sight, the gold-coloured view of the Alps during sunset as a phenomenal quality seems to be significantly different from the functional physical processes that occur in my brain while I am watching the Bavarian mountainside or that occur as the physical and functional substratum of the causal relations between the object

by acquaintance and knowledge by description.

${ }^{9}$ See Eleonore Stump, Aquinas (London - New York: Routledge, 2003), pp. 159-187.

${ }^{10}$ See Richard Cross, Duns Scotus on God (Aldershot: Ashgate, 2005), pp. 59-85.

${ }^{11}$ Cf. Kimble - O' Connor, 'The Argument from Consciousness', pp. 111-112. 
in question and my cognitive apparatus on the other side. The various problems of phenomenal content have been prominently addressed by Frank Jackson's Mary's room parable,${ }^{12}$ which has enriched the discussion of qualitative content ever since. But, in the meantime, certain types of materialism tried to convince us that Jackson's Mary doesn't need to be taken as a rebuttal of physicalism. ${ }^{13}$ These approaches would agree that the apparent differences between phenomenal content on the one hand and physical functions or properties on the other might justify the impression that there is an epistemological gap. However, they would add that this very gap occurs only from an a priori perspective for which, along the lines of highly questionable conceivability arguments, a possible world is conceivable which reveals the very same physical features as our world but has no display of phenomenal states whatsoever. In contrast, a posteriori materialism would emphasize that a priori considerations remain rather irrelevant when it comes to the scientific explanation of consciousness. David Chalmers describes the basic intuition and the main strategy of a posteriori materialism as follows:

In particular, this view locates the gap in the relationship between our concepts of physical processes and our concepts of consciousness, rather than in the relationship between physical processes and consciousness themselves. [...] Proponents of this strategy argue that phenomenal concepts - our concepts of conscious states - have a certain special nature. Proponents suggest that given this special nature, it is predictable that we will find an explanatory gap between physical processes conceived under phenomenal concepts. At the same time, they argue that our possession of concepts with this special nature can itself be explained in physical terms. ${ }^{14}$

The key to get away from a priori dualism is the notion of phenomenal concepts. But what exactly are phenomenal concepts? Some philosophers, like Christopher Hill ${ }^{15}$ and Brian McLaughlin, ${ }^{16}$ have argued

${ }^{12}$ Cf. Frank Jackson, 'Epiphenomenal Qualia', Philosophical Quarterly, 32 (1982), 127-136.

${ }^{13}$ Cf. David Chalmers, The Character of Consciousness (Oxford: Oxford University Press, 2010), pp. 111-124.

${ }^{14}$ Chalmers, Consciousness, p. 305.

15 Christopher S. Hill, Sensations: A Defense of Type-Materialism (New York: Cambridge University Press, 1991).

16 Cf. Brian McLaughlin, 'Color, Consciousness, and Color Consciousness', in Consciousness: New Philosophical Perspectives, edited by Quentin Smith and Aleksander Jokic (Oxford: Oxford University Press, 2003), pp. 97-156. 
that phenomenal and physical concepts play different conceptual roles; but these roles do not correspond to different ontological layers of reality. Others, like Brian Loar, ${ }^{17}$ Michael Tye,${ }^{18}$ or Janet Levin, ${ }^{19}$ regard phenomenal concepts as recognitional concepts whose basic aim is to help us immediately recognize things without the need of referring to background knowledge or any other theoretical knowledge. A third view has interpreted phenomenal concepts in analogy to indexicals (John Perry, ${ }^{20}$ John O'Dea ${ }^{21}$ ) comparing the prima facie epistemic gap between the mental and the physical with those gaps we encounter once we start describing a language that makes use of indexicals as opposed to a language which lacks indexical expressions. A fourth view (associated with Ned Block $^{22}$ or David Papineau ${ }^{23}$ ) tried to treat phenomenal concepts as some sort of quotational concepts where the phenomenal state plays the role of being a mode of representation for either a neuronal state of the brain or the physical properties of a given object of experience. ${ }^{24}$ Thus, defenders of AfC would have to show, according to Kimble and O'Connor, that these materialist strategies aren't successful eventually. Or, to put it in Frank Jackson's parable, proponents of AfC would have to demonstrate that Mary, after having left her black-and-white environment, doesn't just learn how to make use of recognitional concepts, or a special kind of indexicals, or how to be put into a reference situation that allows the use of indirect quotational modes; instead, they need to come up with good reasons to say that Mary acquires additional knowledge and refers to a new set of facts. ${ }^{25}$

${ }^{17}$ Cf. Brian Loar, 'Phenomenal States', Philosophical Perspectives, 4 (1990), 81-108.

18 Michael Tye, Ten Problems of Consciousness: A Representational Theory of the Phenomenal Mind (Cambridge: MIT Press, 1995).

19 Cf. Janet Levin, 'What is a Phenomenal Concept', in Phenomenal Concepts and Phenomenal Knowledge: New Essays on Consciousness and Physicalism, ed. by T. Alter and S. Walter (Oxford - New York: Oxford University Press, 2007), pp. 87-110.

${ }^{20}$ Cf. John Perry, Knowledge, Possibility and Consciousness (Cambridge: MIT Press, 2001).

${ }^{21}$ See John O'Dea, 'The Indexical Nature of Sensory Concepts', in Philosophical Papers, 31 (2002), 169-181.

${ }^{22}$ Cf. Ned Block, 'Consciousness, Accessibility, and the Mesh between Psychology and Neuroscience', in Behavioral and Brain Sciences, 30 (2007), 481-548.

${ }^{23}$ Cf. David Papineau, Thinking about Consciousness (Oxford: Oxford University Press, 2002).

${ }^{24}$ Cf. Chalmers, Consciousness, pp. 309-311; see also Kimble - O'Connor, 'The Argument from Consciousness', pp. 113-117.

${ }^{25}$ Cf. Moreland, Consciousness, pp. 42-43. 
A number of aspects could strengthen the idea that the abovementioned treatment of phenomenal concepts doesn't do justice to their intrinsic features we usually describe when we use phenomenological methods. For instance, it is hard to explain the special status of phenomenal concepts in terms of recognitional concepts since pretty much any concept has the capacity to serve as a recognitional concept. Take the concept of chair, for example. In a Van Inwagen world this concept's extension would not be the entity we usually associate with the word 'chair' but an arbitrary sum of material simples. The notion of chair would not be obsolete, however, but it would serve as a recognitional concept only. And in such a world the same would be true for almost any everyday concept being related to everyday wholes. Although everyday concepts for mesocosmic wholes would have the same status as phenomenal concepts, obvious differences remain between these kinds of concepts, since the concept of chair, table, computer and the like still worked as physical or functional concepts even if they did this job as some sort of conceptual abbreviation in a Van Inwagen world; phenomenal concepts, attached for example to colour-expressions or feelings, seem to belong to another kind. Additionally there is a significant difference between phenomenal concepts and indexicals since the latter's meaning depends crucially and exclusively on the context and, therefore, on the person that is using these expressions. In contrast, Brian Loar's reference to type demonstratives looks pretty much like an illegitimate hybrid conceived of concepts and indexicals.

Imagine, for example, that I have visited the German Parliament together with my wife; both of us have admired the chairs and their colour (which is Reichstags-blue). Both of us have had a phenomenal experience of Reichstags-blue (which is a special colour developed exclusively for the furniture of the German Parliament). While anyone would have to clarify his or her sentences when using indexical expressions while the primary context of their application has changed, I wouldn't have to do this when I am talking to my wife about Reichstags-blue - and not just because we were exposed to the same indexical-solidifying context, but because we had the very same colour-experience. Thus, for both of us there would be no need to replace the colour expressions in the sentence 'Reichstags-blue is brighter than royal blue' with expressions like 'Colour 56 on the $X$ spectrum is more $F$ than Colour 45 on the $X$ spectrum' (with $X$ and $F$ being functional expressions built upon wave length, reflection and the like). But, of course this doesn't show that the 
concept of Reichstags-blue isn't just a mode of representation, while the underlying fact - the dry and sober fact so to speak - is nothing else but colour 56 on the $X$ spectrum. Something more needs to be said here.

Coming from this perspective the strategy Kimble and O'Connor are proposing has some additional merit because they point at a certain tension invoked by phenomenal concept defenders who say that:

(a) a subject of experience has immediate access to the phenomenal content of a phenomenal property (displayed by a phenomenal experience),

(b) this phenomenal property is actually a physical-functional property,

(c) the very same subject of experience doesn't have immediate access to the property in question as a physical-functional property. ${ }^{26}$

Of course, it is not valid to derive 'person $a$ is aware of $x$ being Non- $F$ ' from ' $a$ 's being not aware of $x$ being $F$. Rather, the tension arises from the fact that the property in question has, so to speak, hidden features - those aspects of its nature that aren't transparent to consciousness, although transparency is the significant feature of phenomenal properties. ${ }^{27}$ And, to say the least, properties like those (that are said to have simultaneously open and hidden features) are really puzzling. However, as Kimble and O'Connor admit, the puzzle in question presupposes that a so-called doctrine of revelation is sound which says that the intrinsic nature of phenomenal properties is revealed to us (in its entirety) while we experience this very same property. ${ }^{28}$ Unsurprisingly, the doctrine of revelation has been attacked by a posteriori materialists. But even if we agreed to doubt its overall validity with regard to phenomenal concepts, this doctrine is hard to put aside, since transparency is the key signature of phenomenal properties and phenomenal awareness: It isn't easy to believe that the aching pain I feel has certain features that are hidden from immediate awareness since being brought to immediate attention is the core ingredient that makes pain a phenomenal concept. But again, even if nobody may be puzzled by the notion of hidden aspects there still remains, according to Kimble and O'Connor, a difference in content between the transparent aspects of a phenomenal property and its assumedly hidden physical-functional nature.

\footnotetext{
${ }^{26}$ Cf. Kimble - O'Connor, 'Argument from Consciousness', pp. 118-119.

${ }^{27}$ Cf. Kimble - O'Connor, 'Argument from Consciousness', p. 120.

${ }^{28}$ Cf. Kimble - O'Connor, 'Argument from Consciousness', p. 121.
} 
To benefit from that difference, we have to add a principle of genuine content to the picture: Let us use the above-mentioned case of Reichstagsblue again. Using Hector-Neri Castanedas vocabulary we can simply state that the Reichstags-blue-guise is very different from the colour-56on-the- $X$ spectrum-guise given that guises are the objective content of awareness and consciousness. Within my belief-system and, of course, behaviourally I will respond differently to both guises since they are related to different language games producing different meanings for the phrases in question. But what kind of deeper differences are on the very bottom of my different responses to those guises? Kimble and O'Connor are focusing on one key feature (but perhaps there are more): While phenomenal concepts are simple, physical-functional concepts are structured. ${ }^{29}$ Therefore, it is hard to believe that guises, which differ significantly with respect to their genuine content, should constitute one and the same property. At this point property dualism (at least one version of property dualism) seems to be a more or less reasonable metaphysical response to a semantic and epistemological question.

\section{AFC MODIFIED}

But what would this result do for AfC? Unfortunately, not very much at this point. For premises $\left(2^{\star}\right)$ and (3) require certain features of consciousness that exceed natural explanation. But this time it is the term 'natural explanation' which might undermine AfC. Because, as Kimble and O'Connor have shown persuasively, as long as we have the perspective to come up with fine-grained natural laws which allow us to map phenomenal properties to physical-functional properties we won't need a theistic explanation. ${ }^{30}$ And isn't it this hunger that feeds any version of AfC? However, if there remains no hunger, the only way theism could make use of property dualism would be by some sort of fine-tuning argument which basically says that a universe equipped with laws of nature that allow consciousness to arise is quite improbable if we don't take into account the possible intention of a divine creator. ${ }^{31}$ If this is the sparse result, AfC as a special kind of argument is gone; consciousness is boiled down to an interesting piece of evidence,

\footnotetext{
${ }^{29}$ Cf. Kimble - O'Connor, 'Argument from Consciousness', pp. 126-133.

${ }^{30}$ See also Oppy, 'Moreland's Argument', pp. 200-204.

${ }^{31}$ Cf. Kimble - O’Connor, 'Argument from Consciousness', pp. 133-140.
} 
which, among others, reveals assumedly astonishing qualities of the universe we inhabit. May the theistic philosopher take it from here. Now, to avoid that AfC changes into some subcase of fine-tuning argument three strategies could offer possible solutions, which could help strengthening AfC in its very own right.

Strategy 1) could try to propose the idea that lawlike mapping of phenomenal properties to physical-functional properties cannot count as sufficient explanation since it circumvents an answer to the question why the universe is equipped with laws that call for a mapping of the different types of properties. A comparable strategy seems to consume most parts of Moreland's endeavour of strengthening AfC. To expose this strategy also helps us to understand the beef he has with John Searle's ${ }^{32}$ or Timothy O'Connor's ${ }^{33}$ philosophy of mind. While the former represents an enriched version of naturalism, the later has endorsed and developed a subtle theory of emergence. Both of them offer natural explanations to the occurrence of consciousness (and its features) tout court. Moreland, however, would insist that anything less but dualism and any explanation of the occurrence of consciousness, which is not aiming at dualism, must remain unsatisfying. ${ }^{34}$ But it is very hard to find further evidence in Moreland's writings that would support a reasonable move from property dualism to substance dualism and which would, therefore, justify to move softly from natural explanations to theistic ones. Moreland's sympathies for dualism ${ }^{35}$ might be more plausible if we had access to a world or a situation in which, alluding to a phrase coming from Daniel Dennett, some kind of ectoplasmic spiritual stuff that doesn't have ties to physical entities or properties could be encountered. In other words, if we could really compete against a posteriori materialism based on what we might call a posteriori dualism (based on the experience of spiritual stuff), the idea of lawlike mapping sets of properties to other sets of properties wouldn't do the job of explanation because we would be confronted with the fact that the realities behind those sets could go different, even separate ways. Yet, as long as worlds or situations, in which ectoplasmic spiritual stuff is independent of matter, remain

${ }^{32}$ Cf. Moreland, Consciousness, pp. 53-69.

${ }^{33}$ Cf. Moreland, Consciousness, pp. 70-94.

${ }^{34}$ Cf. Moreland, Consciousness, pp. 51-52, 179-190.

35 For an overview and critique of Moreland's dualistic arguments see Graham Oppy, 'Critical Notice of J.P. Moreland's Consciousness and the Existence of God', EJPR, 3 (2011), 193-212 (pp. 205-211). 
a merely logical possibility, they remain purely fictional and cannot be in the scope of natural explanations.

In contrast, strategy 2) could try to narrow down the notions of natural explanation to the idea of neo-Darwinian explanation, for which change and survival of the species are the core parameters. Although this is a promising way since it excludes any form of explanation referring to design or a creator's intention right from the start, ${ }^{36}$ appealing to phenomenal content alone won't do the trick if one wants to have good reason to say that neo-Darwinian explanations aren't sufficient. For in a neo-Darwinian framework it is still possible to explain the occurrence of phenomenal content as a means to increase the chances of survival and prosperity for any species equipped with cognitive faculties and their biological substratum which allows phenomenal content to occur. This is precisely the reason why anyone who is willing to pick up a fight with neo-Darwinian theories of non-theistic evolution rather shies away from using phenomenal content as a starting point. Alvin Plantinga for example, who has offered an anti-naturalistic argument in different versions, ${ }^{37}$ emphasizes the interesting fact that our cognitive capacities are aimed at truth. The desire for truth - as opposed to wishful thinking, resilience or self-delusion - may be seen as something that remains outside the fence of neo-Darwinian explanations. ${ }^{38}$ But if we move from phenomenal content to the desire for truth in refurnishing AfC, we have actually left AfC for the classic alethological argument ${ }^{39}$ (famously proposed by St. Augustine ${ }^{40}$ and alluded to by St. Anselm). So again, this strategy fails in saving the genuine idea of AfC.

Eventually strategy 3) will take up the pieces of strategy 2) in order to use an entirely different feature of consciousness as a starting point. The

\footnotetext{
${ }^{36}$ See Michael Rea, World Without Design: The Ontological Consequences of Naturalism (Oxford: Oxford University Press, 2004).

37 Cf. Alvin Plantinga, Warrant and Proper Function (Oxford: Oxford University Press, 1993). See also Alvin Plantinga, Where the Conflict Really Lies: Science, Religion, and Naturalism (Oxford: Oxford University Press, 2011), pp. 307-350.

${ }^{38}$ Cf. for example John Haught, God After Darwin. A Theology of Evolution (Boulder: Westview Press, 2000).

${ }^{39}$ It should be added that the alethological argument in its classical form has certain flaws since it seems to foster the idea that God is the truthmaker for everything in saying that God and truth are identical. Maybe Plantinga's version, which remodels the alethological argument within the framework of a fine-tuning-argument, is the best we can get nowadays.
}

${ }^{40}$ Cf. St. Augustine, De libero arbitrio II, 5-39. 
feature in question, however, must be one that relates almost immediately to theistic explanation, i.e. the feature in question must be such that it cannot be understood (epistemologically and metaphysically) without reference to God. Philosophers within the continental tradition, close to German idealism, have pointed to the First-Person-Perspective (FPP) as the core aspect of consciousness we are looking for. ${ }^{41}$ Paradigmatically, the argument, which brings this aspect to our attention, runs as follows:

(1) Human consciousness is based and rooted in a FPP.

(2) FPP constitutes the uniqueness of a person's self-consciousness.

(3) Natural explanations cannot account for uniqueness.

(4) Explanations that cannot account for uniqueness are unsatisfying in the light of an adequate phenomenology of consciousness.

(5) Natural explanations cannot account for the FPP.

(6) Therefore, natural explanations are unsatisfying.

The phrase 'uniqueness' in this case means that an entity is absolutely irreplaceable. Well, this sounds somewhat counter-intuitive, because we may say that any person is replaceable; there are enough people on the planet that could fill in my positions, take up my profession or even be the head of my family. But all these things are mere functions and roles, which are attached to myself, more or less accidentally. But for the unique perspective on the world, which my self represents, I am truly unique and irreplaceable. ${ }^{42}$ If there is something substantially irreducible about de-se-sentences it has to do with the uniqueness of the FPP. Given that this is a sound circumscription of uniqueness the question remains why physical-functional concepts or properties may remain insufficient in furnishing an explanation of its origin, extension, constituents or phenomenal qualities. Here is, indeed, the sticky part of the argument. Because any answer would have to lay the foundation for a new version of property dualism in emphasizing that the properties that account for the uniqueness of EPP are significantly different from physical-functional properties. But how so? A response will have to start with the idea that physical-functional properties don't haveirreplaceable constituents - quite

${ }^{41}$ Cf. Gunnar Hindrichs, Das Absolute und das Subjekt: Untersuchungen zum Verhältnis von Metaphysik und Nachmetaphysik (Frankfurt a.M: Klostermann, 2008), pp. 227-249.

${ }^{42}$ For an elaborate version of this idea see Geoffrey Madell, 'Materialism and the First Person', in Minds and Persons, ed. by Anthony O'Hear (Cambridge: Cambridge University Press, 2003), pp. 123-139 (esp. 130-132). 
the opposite: Functions permit perpetuation and repetition, which allows the exchange of elements or parts. Another indication to distinguish the different aspects of FPP on the one side and functional properties on the other could be that any function takes time to process whereas the connection between transparent phenomenal experiences and a meta-awareness of myself experiencing something occur and coincide instantaneously and simultaneously. Still, there are some loose ends in this argument. First of all, the notion of being explanatorily unsatisfying per se does not entail any indication that a theistic explanation would offer a solution. Secondly, even if we could move from the fact that a natural explanation remains unsatisfying straightforwardly to a theistic explanation, one would be curious to see exactly how theistic concepts will do their job in explaining the uniqueness of FPP. A conceptual offer comes from German idealism again: To Hegel, for instance, it seemed metaphysically and epistemologically apparent that God as the absolute FPP is the ontological soil any finite FPP is rooted in. If God is seen as a principle of omni-subjectivity, he could help explaining the occurrence of FPPs in a universe which, taken from its purely physical side, might have evolved without any FPP since the laws of nature that have guided its evolution cannot account for the origin of FPPs.

But, the mentioned loose ends could still threaten the entire validity of AfC. And to successfully tie these ends together might be complicated. So, it might be worthwhile to ask whether the uniqueness-approach can be strengthened and somewhat simplified. A promising way is Hegel's combination of self-consciousness and morality, ${ }^{43}$ which can be transformed into the following argument:

(1) Human consciousness is based and rooted in a FPP.

(2) FPP constitutes the uniqueness of a person's self-consciousness.

(3) The uniqueness of self-consciousness becomes apparent in moral experiences.

(4) Moral experiences are based on moral properties that aren't identical (maybe not even supervenient) with physical-functional properties.

(5) Naturalistic explanations are rigorously related to physicalfunctional properties.

(6) Naturalistic explanations aren't related to moral properties.

${ }^{43}$ Cf. Georg W.F. Hegel, Phänomenologie des Geistes, ed. by W. Bonsiepen (Hamburg: Meiner, 1988), pp. 395f. 
The crucial premises are apparently (3) and (4). Premise (3) combines uniqueness with moral experience. But how so? Hegel, along with other traditions, underlines that the experience of moral properties results in an awareness of and a call for duty, which picks me as its addressee irrevocably. In this case uniqueness is introduced in terms of being irrevocably referred to or being irreplaceably called to action. So, it might not be too hard to show how premise (3) could be true: Just try to imagine being the witness of an accident. To be called to rescue injured people is irrevocably addressed to myself even if other persons are available to step in. Furthermore, even if they step in for me, this would not take away the one single part of the duty that has been addressing me, because there isn't an experience of duty, which is not, at the very same instant, my duty. Intuitively, Hegel is right in basing the experience of FPP and uniqueness on the experience of duty. Similarly, premise (4) will be quite convincing as well, once we consider it impossible to reduce moral properties to physical properties, because we have good reasons to claim that moral guises are intrinsically and structurally different from physical-functional properties. Precisely here is the point where we can make use of the lessons we learned previously in emphasizing the doctrine of revelation and the principle of genuine content. In this case, the difference becomes obvious once we agree that moral properties present something as good or desirable while physical properties are aspects or features of what is presented as good or desirable. Since the presenting instance and what is presented cannot be identical we must not assume that moral properties are identical to physical-functional properties. Furthermore, we don't even have the slightest piece of evidence to think that moral properties supervene on physical properties, because we can easily imagine a world with the very same physical properties realized and instantiated but without the display of moral properties tout court. If Hegel's idea is sound, we may have found a way to improve AfC significantly. The lessons we have learned in defending phenomenal consciousness against a posteriori materialism is still present. However, strategically we have moved from consciousness as such to ethical awareness and morality.

But why isn't this version of AfC not just an argument from morality ${ }^{44}$ with some AfC icing on the top? In Hegelian terms the answer would be that a naturalistic explanation couldn't shed any light on the constitution

${ }^{44}$ Cf. Paul Copan, 'The Moral Argument', in The Rationality of Theism, ed. by Paul Copan and Paul Moser, pp. 149-174 (esp. 152-153). 
of a FPP, which is the crucial presupposition for the moral realm that rests on responsibility and conscience. In other words: The feature that allows us to perceive what makes consciousness unique is conscience. And this is something that goes beyond qualitative experiences but is, nevertheless, related to them. Additionally, a Hegelian version of AfC will be more than another variation of fine-tuning arguments if we have evidence that for any conscience-gifted FPP we need to postulate a more or less immediate participation in - what Hegel calls - the absolute. At this point we can offer, at least, a conditional to save AfC as a genuine argument: If conscience as a characteristic feature of consciousness (in its overall ethical and intellectual aspects) offers a unique quality, which cannot be understood correctly if the conscience's perspective isn't rooted in an 'absolute' dimension, a non-theistic 'explanation' of consciousness won't suffice.

\section{CONSCIOUSNESS AND DIVINE CONSCIOUSNESS}

That there might be a chance to improve AfC is not exclusively good news for the theist if any improvement is based on knowledge arguments in the long run, because at this very point one could get pushed into Nagasawa's trap, which in a more detailed but still condensed version can be circumscribed as follows: ${ }^{45}$

(1) The acquisition of certain concepts $C$ implies gaining knowledge; and the lack of certain concepts $C$ implies a lack of certain knowledge.

(2) There is at least one situation in which a rational being a lacks certain concepts (because of a situation or context $S$ ).

(3) There is at least one situation in which a rational being a lacks certain knowledge.

At first glance, (3) doesn't seem to be a huge problem. However, if we should have a reason to think that God lacks certain concepts humans do have (atheistic philosophers like Michael Martin ${ }^{46}$ have introduced the concept of envy or fear, because it seems in order to understand these concepts you need to have had the real experience of envy or fear), he would lack

\footnotetext{
${ }^{45}$ Cf. Nagasawa, God and Phenomenal Consciousness, pp. 120-122.

${ }^{46}$ Cf. Michael Martin, 'Conflicts Between the Divine Attributes', in The Impossibility of God, ed. by M. Martin and R. Monnier (Amherst - New York: Prometheus, 2003), pp. 242-257.
} 
certain knowledge as well. And therefore God wouldn't be omniscient. The theist is confronted with some kind of dilemma: In case AfC works (despite the above-mentioned problems and challenges), it originates from a knowledge argument whose structure could backfire and undermine classic theism, at least certain constituents of classic theism. If AfC does not work, however, the theist would not have to face this particular danger at that point but he might nevertheless lose a good piece of evidence in favour of God's existence. So, is it wise to shy away from knowledge arguments as such in order to save divine omniscience eventually?

It is interesting to notice that from within the philosophy of mind we may get a helping hand for escaping this very problem, i.e. the first horn of the dilemma. In his recent book Michael Tye has expressed dissatisfaction with the idea of phenomenal concepts. For phenomenal concepts won't help the a posteriori materialist explain the special aspects and features of phenomenal experiences, because as concepts they don't stick out. ${ }^{47}$ Phenomenal concepts according to Tye are, like other concepts, open to reference confusion and concept sharing. For example, in applying a concept to a given phenomenal experience we may be insecure which concept to pick if the situation is complex..$^{48} \mathrm{And}$, on the other hand, we can use the phenomenal concepts we have to discuss certain problems with someone who may not have had a certain colour experience but who may know from books and who may have learned from third person testimony that, for example, the colour of German post offices is yellow. ${ }^{49}$ Tye's very own solution is to abandon the idea of phenomenal concepts as a means to approach what seems to be special about qualitative content. Instead, he turns to an interesting distinction inside the concept of knowledge, making a difference between knowing facts and knowing things (which Tye equals with knowledge by acquaintance). Frank Jackson's Mary in this perspective would be a person that knows all the relevant physical facts about colours but who lacks phenomenal experience and, therefore, lacks certain knowledge of things:

There is a kind of knowledge of the color of red that is not given to us by our knowledge of all the relevant physical facts. The knowledge we get by acquaintance. There is a kind of knowledge of the color red that is not given to us by our knowledge of all the relevant physical facts. The

\footnotetext{
47 Tye, Consciousness Revisited, p. 56.

${ }^{48}$ Cf. Tye, Consciousness Revisited, p. 45.

${ }^{49}$ Cf. Tye, Consciousness Revisited, pp. 63-69.
} 
knowledge we get by acquaintance with red is logically independent of our knowledge of truths. Indeed, it is physically possible for someone (for example, Mary in her black-and-white-room) to know all the physical facts pertaining to the experience of red and not know red (in the relevant sense of 'know'). Thus, knowing the relevant facts does not in itself enable us to know red rather than green..$^{50}$

Addressing the idea of knowing things versus knowing facts could be Tye's version of having the cake and eating it, too. Because in the light of Tye's distinction Frank Jackson's poor Mary appears to be, let's use Nagasawa's phrase, ${ }^{51}$ (only) prima facie omniscient with regard to the facts one could know about colours. Nevertheless, according to Tye, Mary lacks a certain knowledge of things (which is the access mode we are in whenever we have a colour experience)..$^{52}$ So, Mary's knowledge wasn't perfect to begin with. ${ }^{53}$ Although it parts ways with what Tye said about Mary's case, it sounds just right if we suppose that ultimately knowledge of facts must be rooted in knowledge of things. Therefore, we can as well say that Mary isn't ultima facie omniscient, even if we can admit that she doesn't gain knowledge of facts after her release.

But how could Mary's situation help us in escaping what I have called the Nagasawa trap? For some philosophers God's apparent lack of knowing how it is to be me (according to Grim) or how it is to feel envy (according to Martin) puts a serious threat to divine omniscience. While Nagasawa holds that God could be held responsible for omniscience deficits only if it ever were within his epistemic powers to know such truths, ${ }^{54}$ so that in the end neither Grim nor Martin would have the epistemic right to put God on trial, I would like to propose the idea that whatever they call a lack of knowledge is measured against the rather imperfect standards of propositional knowledge (a term which I want to use to broaden Tye's notion of knowledge of facts). Indeed, there are good reasons to think that divine consciousness performs its cognitive powers predominantly, if not exclusively, as the knowledge of things. Theologically - and this may turn Tye's conceptual distinction from heads to tails - it is sound to think that knowledge of things is

\footnotetext{
50 Tye, Consciousness Revisited, p. 139.

${ }^{51}$ Cf. Nagasawa, God and Phenomenal Consciousness, p. 120.

52 Cf. Tye, Consciousness Revisited, p. 119.

${ }^{53}$ Cf. Nagasawa, God and Phenomenal Consciousness, pp. 125-128.

${ }^{54}$ Cf. Nagasawa, God and Phenomenal Consciousness, pp. 21-23 and 58-73.
} 
superior to knowledge of propositions and that an ultimately perfect and eternal being has simultaneous knowledge of things with knowledge of facts being a surrogate only for those beings that exist in time and are therefore bound to memory, derivation and inference.

Now, what are the benefits of this view? Any omniscience as well as any foreknowledge problem seems to arise from the notion of propositional knowledge. Questions like whether or not God knew yesterday that I am wearing a necktie today are tied to the concept of propositional knowledge. We can undermine this kind of questions and their paradoxical if not dialectical answers if we assume that God doesn't have propositional knowledge (at least not primarily or not in the ways in which we have propositional knowledge). Especially foreknowledge problems are crucially linked to propositions and get sharpened by necessity-expressions. So, if we had reasons to say that divine knowledge is not appropriately, at least not fully captured by expressions of propositional knowledge we might see a way to avoid theistic fatalism. The problem of theistic fatalism arises from a conditional: If God (now or eternally) knows that $p$ will occur tomorrow, then the occurrence of $p$ cannot be within the range of an open future, i.e. within the range of significant freedom which would have the capacity to bring about non- $p$. But what if God, once we take the phrases literally, does not know that $p$ will occur but rather has some sort of knowledge by acquaintance of what the substance behind $p$ is? If the latter were true, we would have no reason to say that God's infallible knowledge of facts causes an event to occur since knowledge by acquaintance is meant to be a specific sort of accompanying, non-inferential knowledge, which per se cannot have any causal effect.

This idea, however, may not be easy to accept; and some will ask if we have reasons to assume that God doesn't have propositional knowledge (at least not primarily) and how God performs any cognitive activity. For the outline of an answer we will find some precious hints in Aquinas to support the idea of a primary and specifically divine knowledge of things (a term that shall be used to describe the ontological side of a knowledge of things). To Aquinas discursive knowledge (which is the result of propositional knowledge) would destroy divine simplicity because in knowing propositions there would be parts within divine knowledge. ${ }^{55}$ Furthermore, propositional knowledge includes knowledge gained

${ }^{55}$ Cf. Aquinas, S.Th. I q. 14 a 7. 
by inferring and deriving conclusions, whereas divine knowledge is absolutely immediate and, so to speak, basic. The closest notion of knowledge that could ever fulfil the standards of divine simplicity is knowledge of things. According to Bertrand Russell's famous definition there are situations in which knowledge of things is as immediate as exhaustive, although it seems to be non-conceptual (or, at least, pre-conceptual) and non-derivative. ${ }^{56}$ Of course, we may wonder how divine knowledge of things can keep divine simplicity intact although there is a plurality of things or substances in this universe. The answer to that question is a common denominator of medieval philosophy: the primary thing God is acquainted with is his very own essence. ${ }^{57}$ Therefore, divine knowledge is superior, perfect, instantaneous and complete, for within the knowledge of his very own essence he knows everything else (taken literally: every-thing else) by acquaintance. Admittedly it is not easy to even get a glimpse of this mode of knowing. Aquinas offers an interesting model which shall be extended and given the form of a thought experiment: Imagine yourself as being some kind of advanced mystic. After years of exercise and training you have the unique experience of being at the very centre of everything while experiencing no passage of time (within yourself) and no unbridgeable distances in space any longer. Nevertheless you would still be able to see the differences of things you are acquainted with in this instantaneous experience. But the point of reference for measuring any difference and diversity would be you as the very centre of this experience. Comparably, God perceives in an instantaneous mode, in an unsurpassable 'now' the diversity and difference of things as they appear through the lenses of his very essence. ${ }^{58}$ If God has propositional knowledge, the only adequate concept he could use would be the non-exhaustive concept of his own essence - with the essence of things filtered through the knowledge of his own essence. But how could this avoid fatalism? A first response says that the modus-ponens-result, which derives the necessity of an event from divine infallibility, cannot be correct, given that the conceptual

${ }^{56}$ Cf. Russell, The Problems of Philosophy, p. 31.

${ }^{57}$ Cf. Aquinas, S.Th. I q. 14. a. 4-6.

${ }^{58}$ I also assume that this could be one way to make sense of Linda Zagzebski's fascinating idea of divine omnisubjectivity which she has introduced to make individual De-seknowledge accessible for the divine knower. See Linda Zagzebski, 'Omnisubjectivity', Oxford Studies in Philosophy of Religion, Vol. 1, ed. by Jonathan Kvanvig (Oxford: Oxford University, 2008), pp. 231-247. 
form of the conditional, which expresses knowledge of facts, isn't a valid depiction of the divine state of knowledge. Thus, the transfer of necessity from the antecedent to the subsequent part of the conditional needs not to be accepted. But isn't there anything more to say about the state of divine knowledge apart from the above-mentioned negative answer that pointed to possible failures in conceptualizing divine knowledge?

Perhaps John Duns Scotus's exposition of the problem will shed some additional light; in accordance with Aquinas and others Scotus agrees that the divine essence is the primary thing God is acquainted with. It is as primary for him as God's being is the ultimate goal for every human action. And in analogy to the fact that the presence of God's being as the ultimate goal in every human action does not disturb humans in directing their will to finite things, God's knowledge of things isn't disturbed by knowing his very own essence as the primary object. ${ }^{59}$ Furthermore, within the divine essence the finite beings are presented ${ }^{60}$ while this presence relates them to divine infinity ${ }^{61}$ so that this very infinity shapes their finitude $\mathrm{e}^{62}$ and therefore their being distinct from God. ${ }^{63}$ Scotus insists that God knows individual substances by acquaintance. But since individual substances are finite and seated in space and time, they are present to an eternal God in their (what we may call) counterparts, ${ }^{64}$ which are their individual essences. ${ }^{65}$ However, this doesn't make the individual substances eternal. Having their essences as eternal counterparts is just the mode of their being presented to and known by an eternal God. ${ }^{66}$

However, this is the point where Scotus parts ways with Aquinas and the Boethian idea of eternity. For Scotus the future cannot be simply present and, therefore, cannot be an equivalent relatum of the eternal now, which is God's very own privileged point of view. Since eternal co-presence presupposes that both sides of the relation are actual, God cannot be co-present with future events. ${ }^{67}$ What sounds like Scotus's

${ }^{59}$ Cf. John Duns Scotus, Ord. I, Dist. 35, q. unica, n. 29.30.

${ }^{60}$ Cf. John Duns Scotus, Ord. I, Dist. 35, q. unica, n. 14.15.

${ }^{61}$ Cf. John Duns Scotus, Ord. I, Dist. 35, q. unica, n. 32.

${ }^{62}$ Cf. John Duns Scotus, Ord. I, Dist. 35, q. unica, n. 16.17.20.

${ }^{63}$ Cf. John Duns Scotus, Ord. I, Dist. 35, q. unica, n. 26.

${ }^{64}$ Cf. John Duns Scotus, Ord. I, Dist. 35, q. unica, n. 44.45.

${ }^{65}$ Cf. John Duns Scotus, Ord. I, Dist. 35, q. unica, n. 31.32.

${ }^{66}$ Cf. John Duns Scotus, Lect. I, Dist. 36, q. unica, n. 22.

${ }^{67}$ For a substantial analysis see Pascal Massie, 'Time and Contingence in Duns Scotus', in The Saint Anselm Journal, 3 (2006), 17-31. 
appreciation of some form of presentism turns out to be a sophisticated alternative to a temptation created by the Boethius-Aquinas way of interpreting divine eternity, a temptation that consists in making contingent entities or events somehow eternal before God's point of view. For Scotus, time is not like a frozen circle around a centre, which is God's perspective. Rather it resembles a moving flow in the shape of a circle around the divinely immovable spot. ${ }^{68} \mathrm{God}$ is not subject to time; but the order of time is relevant to him in his very own eternal copresence. Thus, what is necessary and eternal is seen by the divine mind as an uninterrupted pattern in a, let us use this somewhat problematic analogy, panoramic visual field, while contingent things are changing, often interrupted and yet related patterns which aren't by any means continuous appearances in this field. ${ }^{69}$ Avoiding the danger of making contingent entities eternal, Scotus emphasizes that future contingents aren't predominantly presented to the divine intellect, which (as any) intellect refers to what is given, i.e. actual. So, it is the divine will that relates to future contingents, making them determinate. ${ }^{70}$ And future contingents are ontologically present to the divine will as intentional objects. The key mistake of theistic fatalism, in Scotus's view, is to treat future events as a given to a past state of divine knowledge. But future events aren't a given since they are not actual (nevertheless as potentials they are in some way existing and can serve as intentional objects). And, additionally, there is no past stage of divine knowledge, since God is not subject to time but present to himself in an eternal now.

But how does this idea refer back to the predominance of the knowledge of things? Didn't we talk of future events although we tried to get away from any expressions that pictured divine knowledge in terms of knowing facts? Maybe the final story can be told like this: In their essences individual things and their changes are to be cognized as centres for patterns of properties with potential properties (as intentional parts) replaced by actual properties - a replacement which depicts the order of time and temporal change in the tenseless view of divine eternity. Whereas, in our tensed view those properties are the truthmakers of facts or are the potential truthmakers of future events. Since we do not have a divine perspective, the continuance of a thing enduring its changes

\footnotetext{
${ }^{68}$ Cf. John Duns Scotus, Lect. I, Dist. 39, qq. 1-5, n. 85-87.

${ }^{69}$ Cf. John Duns Scotus, Lect. I, Dist. 39, qq. 1-5, n. 65.

${ }^{70}$ Cf. John Duns Scotus, Lect. I, Dist. 39, qq. 1-5, n. 64.
} 
comes to us as some abstraction. For God, however, the essences of things are the immediate objects of his privileged knowledge. If God should have further knowledge of propositions in addition to the knowledge of things, this propositional knowledge has to be conceptually different from our propositional knowledge (since God sees everything through the lenses of his essence) and, to say the least, must transform tensed propositions into tenseless ones (at least many medieval theologians voted for such a transformation).

But what can this picture of divine knowledge do for the Nagasawa problem? Omniscience, defined in accordance with so-called knowledge arguments, seems to be related to the set of all true propositions. Indeed, if divine knowledge were of that kind, even one element missed by divine knowledge would raise the suspicion that God is seriously lacking omniscience. Instead of discussing whether or not God's omniscience could survive if it were related to only a subset of all true propositions, medieval philosophers have painted another picture: at the backside of the set of all propositions there is the set of all actual (and possible) individuals through their essences. In knowing all essences by acquaintance God knows everything there is to know even though he doesn't have the propositional knowledge we have. In other words: God looks at the universe in a very different way. Recalling theological traditions we have reason to think that his knowledge by acquaintance is way superior to our modes of knowing, while propositional knowledge is needed where immediate access is lost or the simplicity of the state of knowing cannot be granted. One indicator that helps us to subscribe to this view is that knowledge by acquaintance is immediate, whereas propositional knowledge is not. Another one would be to say that propositional knowledge cannot really grasp the individuality of individual substances since for propositional knowledge individuals appear to be instances of universals (with propositions being the offspring of universals), while within divine knowledge individual essences are grasped in their individuality, since they aren't perceived as cases of something universal, because they are measured by the standards of the divine essence, which is the instance of pure singularity.

\section{CONCLUSION}

Now with this emphasis on the difference between knowing things and knowing propositions we may eventually have to deal with the 
question whether we have undermined AfC completely. As it appears the theologically speculative idea of divine knowledge was built upon the graveyard of knowledge arguments. Do I have to bury AfC once we move away from the premises of knowledge arguments as such? Well, this might not be the last word here. Looking at the philosophy of consciousness from a distance, anyone will notice certain cycles of loading off problems; eventually the dualism of facts and concepts was pushed to the duality of knowing facts and knowing things. And as long as there is some duality at work we will always have the space to come up with conceivability arguments. In this case we should wonder whether or not there is a possible world in which people have knowledge of facts without knowledge of things. If knowledge of facts is necessarily rooted in knowledge of things we would be forced to imagine something truly impossible. But maybe there is no necessary connection (at least we can think of God being a very prominent exemption) so that the natural connections between knowledge of facts and knowledge of things are typical for human beings and animals inhabiting the actual world. Based on this assumption we can imagine a world without knowledge of things. Any form of cognitive processing would be somehow derivative and mediated through certain detour calculations. A world like that would resemble a robot world presenting an encyclopedia of (true) propositions without having ever touched the ground of knowing things. But what exactly makes the difference between this world and our world where knowledge of things is not an unusual though sometimes rare access-mode? There are some reasons to believe that the First-PersonPerspective makes the difference since this perspective seems to be at the very bottom of knowing things since it is the ultimate role-model of knowing things. ${ }^{71}$ If we could come up with further reasons to believe that FPP is the ultimate instantiation or even the prerequisite for the knowledge of things, we could start the engine of AfC again. ${ }^{72}$

${ }^{71}$ Cf. Russell, Problems of Philosophy, p. 34.

72 Acknowledgment: This paper was originally presented in Munich, at a conference for the Analytic Theology Project, generously funded by the John Templeton Foundation. 